\title{
Uso de fitoterápicos e demais componentes vegetais e minerais na fabricação de produtos odontológicos naturais: Revisão de literatura
}

\author{
Use of phytotherapy and other vegetable and mineral components in the manufacture of natural \\ dental products: Literature review
}

Uso de fitoterapia y otros componentes vegetales y minerales en la fabricación de productos dentales naturales: Revisión de literatura

\author{
Júlia de Jesus Domingues \\ ORCID: https://orcid.org/ 0000-0003-4420-5545 \\ Faculdade Patos de Minas, Brasil \\ E-mail: julia.10671@alunofpm.com.br \\ Letticya Thandara Alves Oliveira \\ ORCID: https://orcid.org/ 0000-0001-5169-7475 \\ Faculdade Patos de Minas, Brasil \\ E-mail: letticya.06583@alunofpm.com.br \\ Marcelo Dias Moreira de Assis Costa \\ ORCID: https://orcid.org/0000-0001-9148-3674 \\ Universidade Federal de Uberlândia, Brasil \\ E-mail: marcelodmac@yahoo.com.br \\ Luciana de Araújo Mendes Silva \\ ORCID: https://orcid.org/ 0000-0003-0311-1323 \\ Faculdade Patos de Minas, Brasil \\ E-mail: luciana.silva@ faculdadepatosdeminas.edu.br \\ Fernando Nascimento \\ ORCID: https://orcid.org/ 0000-0003-3568-3887 \\ Faculdade Patos de Minas, Brasil \\ E-mail: fernando.nascimento@faculdadepatosdeminas.edu.br \\ Lia Dietrich \\ ORCID: https://orcid.org/ 0000-0001-7887-8591 \\ Clínica Privada, Brasil \\ E-mail: dietrichlia.ld@gmail.com
}

\begin{abstract}
Resumo
Os fitoterápicos e os demais componentes vegetais e minerais definem-se como uma forma de utilização de produtos naturais para o tratamento de doenças, possibilitando diversos benefícios aos usuários, desde que utilizados corretamente. O objetivo dos fitoterápicos é de cura, prevenção ou minimização das sintomatologias das doenças, além de serem mais acessíveis à população do que os medicamentos sintéticos. Dessa forma, os produtos naturais, por possuírem atividades antifúngicas, antimicrobianas e antineoplásicas são considerados uma ótima alternativa em tratamentos bucais, auxiliando os cirurgiões dentistas e os pacientes no controle do biofilme. Nesse contexto, o objetivo deste trabalho é esclarecer os benefícios e a efetividade de alguns produtos odontológicos naturais e suas contra-indicações, além de explicar as vantagens e desvantagens de se utilizar tais produtos. A metodologia desenvolvida no presente trabalho constituiu-se em realizar uma revisão de literatura narrativa, qualitativa, utilizando artigos encontrados em bases de dados científicos, como: Scielo, Bvsalud, Redalyc e Sciencedirect. O uso dos fitoterápicos demonstram como resultado uma série de vantagens e desvantagens as quais oscilam dependendo da forma que foram empregados, estes apresentam diversos benefícios tanto para os pacientes quanto para os serviços públicos de saúde o que facilita sua aderência nesses serviços. Conclui-se que a utilização, de forma correta dos fitoterápicos é uma ótima terapia alternativa no tratamento de doenças bucais e fornece uma serie de benéficos para a saúde bucal, visto que os produtos naturais são mais acessíveis por possuírem menores preços que os produtos sintéticos além de apresentarem menor toxicidade.
\end{abstract}

Palavras-chave: Higiene bucal; Produtos biológicos; Odontologia; Saúde bucal; Prevenção primária.

\footnotetext{
Abstract

Phytotherapics and other plant and mineral components are defined as a way of using natural products for the treatment of diseases, enabling various benefits to users, provided they are used correctly. The purpose of herbal medicines is to cure, prevent or minimize the symptoms of diseases, in addition to being more accessible to the
} 
population than synthetic medicines. Thus, natural products, because they have antifungal, antimicrobial and antineoplastic activities, are considered a great alternative in oral treatments, assisting dental surgeons and patients in the control of biofilm. In this context, the objective of this work is to clarify the benefits and effectiveness of some natural dental products and their contraindications, in addition to explaining the advantages and disadvantages of using such products. The methodology developed in the present work was to carry out a narrative review of the literature, being researched in scientific databases, such as: Scielo, Bvsalud, Redalyc and Sciencedirect. The use of herbal medicines demonstrates as a result a series of advantages and disadvantages which fluctuate depending on the way they were used, they present several benefits for both patients and public health services, which facilitates their adherence to these services. It is concluded that the correct use of herbal medicines is a great alternative therapy in the treatment of oral diseases and provides a series of benefits for oral health, since natural products are more accessible because they have lower prices than synthetic products in addition less toxicity.

Keywords: Oral hygiene; Biological products; Dentistry; Oral health; Primary prevention.

\section{Resumen}

Los fitoterápicos y otros componentes vegetales y minerales se definen como una forma de utilizar productos naturales para el tratamiento de enfermedades, permitiendo diversos beneficios a los usuarios, siempre que se utilicen correctamente. La finalidad de las medicinas a base de plantas es curar, prevenir o minimizar los síntomas de las enfermedades, además de ser más accesibles a la población que las medicinas sintéticas. Así, los productos naturales, por tener actividades antifúngicas, antimicrobianas y antineoplásicas, se consideran una gran alternativa en los tratamientos bucales, ayudando a los cirujanos dentales y pacientes en el control de la biopelícula. En este contexto, el objetivo de este trabajo es esclarecer los beneficios y efectividad de algunos productos dentales naturales y sus contraindicaciones, además de explicar las ventajas y desventajas de utilizar dichos productos. La metodología desarrollada en el presente trabajo fue realizar una revisión narrativa de la literatura, siendo investigada en bases de datos científicas, tales como: Scielo, Bvsalud, Redalyc y Sciencedirect. El uso de medicamentos a base de hierbas demuestra como resultado una serie de ventajas y desventajas que fluctúan según la forma en que fueron utilizados, presentan varios beneficios tanto para los pacientes como para los servicios de salud pública, lo que facilita su adherencia a estos servicios. Se concluye que el uso correcto de las hierbas medicinales es una gran alternativa terapéutica en el tratamiento de las enfermedades bucodentales y aporta una serie de beneficios para la salud bucal, ya que los productos naturales son más accesibles porque tienen precios más bajos que los productos sintéticos además de menor toxicidad.

Palabras clave: Higiene bucal; Productos biológicos; Odontología; Salud bucal; Prevención primaria.

\section{Introdução}

A inserção dos produtos naturais e da fitoterapia como prática integrativa e complementar à saúde vêm sendo reconhecida no exercício do cirurgião-dentista desde 2008, pela Resolução ${ }^{\circ}$ 082/2008, sendo regulamentada pelo Conselho Federal de Odontologia e inserida pela Política Nacional de Práticas Integrativas e Complementares (PNPIC) do Ministério da Saúde (Monteiro \& Fraga, 2015; Evangelista et al., 2013). A fitoterapia é denominada como uma ciência que estuda a utilização de produtos naturais ou partes destes como tratamento de doenças; quando indicadas corretamente, oferecem benefícios para a saúde de quem as utiliza (Aleluia et al., 2015). Esse tipo de terapia com produtos naturais tem ganhado grande espaço no meio odontológico, devido aos produtos naturais possuírem atividade terapêutica elevada, baixa toxicidade e biocompatibilidade comprovada cientificamente, paralelamente aos medicamentos convencionais, sendo utilizadas em fins diversificados, dentre eles, a utilização na saúde bucal (Gomes et al., 2002; Monteiro, 2012; Castilho, Murata \& Pardi, 2007).

Apesar de a medicina moderna estar bastante desenvolvida, a Organização Mundial de Saúde (OMS) reconhece que a maioria da população do país ainda é refém da medicina tradicional na atenção primária (Valente et al., 2009). Os fitoterápicos possuem finalidade de cura, prevenção ou redução da sintomatologia das doenças, sendo mais acessíveis à população do que os medicamentos de síntese química, que geralmente são mais caros devido a suas patentes tecnológicas envolvidas (Evangelista et al., 2013; Castilho, Murata \& Pardi, 2007). A procura por produtos naturais semelhantes aos que possuem substâncias sintéticas está crescendo muito. Isso faz com que várias pesquisas sejam desenvolvidas para mostrarem as substâncias com menor efeito adverso e baixo custo, sendo que os constituintes dos produtos naturais podem ser utilizados em drogas como matéria prima e em compostos farmacologicamente ativos (Valente et al., 2009; Dinguesleski et al., 2015).

Conforme mencionado, o consumo de produtos naturais na saúde, no mundo moderno, vem crescendo bastante, 
principalmente pela população vegana, vegetariana e naturismo, que têm buscado por produtos mais naturais, expandindo a utilização das destes e de fitoterápicos (Monteiro \& Fraga, 2015; Saliasi et al., 2018). Os veganos podem ser definidos como pessoas que não ingerem nenhum alimento ou produtos de origem animal; já os vegetarianos restringem-se somente à alimentação não derivada de animais (Ducatti, 2020). Dessa maneira, a população vegana busca por produtos naturais e a indústria odontológica vem atendendo as exigências desse público, desenvolvendo produtos para higiene oral, produzidos utilizando componentes de origem natural, além de procurar produtos menos tóxicos e mais biocompatíveis, características essas encontradas em produtos naturais e na fitoterapia (Dinguesleski et al., 2015).

Os produtos naturais têm sido uma das maiores fontes de descoberta de atividades antifúngicas, antimicrobianas e antineoplásicas; por possuírem essas características são considerados uma boa alternativa em tratamentos bucais, potencializando a utilização dessa terapêutica e auxiliando os cirurgiões-dentistas e os pacientes (Gomes et al., 2020; Castilho, Murata \& Pardi, 2007). Através da utilização dos fitoterápicos, vem sendo criados vários programas preventivos e curativos para o controle do biofilme dental, que é um dos fatores no desenvolvimento da doença periodontal e da cárie (Bussadori, 2013). Vários cirurgiões dentistas têm adotado essa filosofia de utilização de produtos naturais, visando a uma melhora na saúde bucal de crianças e da população geral, porém mesmo estando aptos para a terapia fitoterápica na Odontologia, os cirurgiões dentistas ainda encontram desafios a serem enfrentados (Monteiro \& Fraga, 2015; Saliasi et al., 2018).

Este trabalho possui o intuito de realizar uma revisão de literatura narrativa a respeito dos diversos tipos de produtos de higiene oral naturais, disponíveis no mercado atualmente. Auxiliando desta forma tanto o cirurgião dentista quanto a população sobre a vasta disponibilidade de produtos naturais no mercado, os quais podem ser utilizados para auxiliar na manutenção da saúde bucal.

Sendo assim, o objetivo desse trabalho é levar aos leitores o conhecimento dos produtos com componentes naturais, visto que possuem menor custo e baixa toxicidade. De forma mais específica, esclarecer os benefícios e efetividade de alguns produtos odontológicos naturais e suas contra-indicações, além de explicar as vantagens e desvantagens de se utilizar tais produtos.

\section{Metodologia}

Foi realizada uma revisão de literatura narrativa, qualitativa, baseada na análise de 26 artigos científicos, os quais foram adquiridos em bases de dados on-lines tais como, Pubmed, Scielo, Bvsalud, Redalyc e Sciencedirect. Tais artigos foram encontrados através da busca das palavras chaves: Plantas medicinais, Higiene bucal, Produtos biológicos, Odontologia. Todos os artigos utilizados se encontravam na língua portuguesa.

\section{Revisão de Literatura}

\subsection{Produtos naturais na Odontologia e principais ativos}

Ultimamente o interesse por produtos naturais vem crescendo gradativamente, pelo fato de as mesmas serem biocompatíveis e possuírem maior atividade farmacológica e menor toxicidade (Monteiro \& Fraga, 2015; Machado \& Oliveira, 2014; Moreira, Ferreria \& Hashizume, 2012). A fitoterapia vem sendo bastante utilizada no que se refere aos cuidados da saúde, porém quando se fala em saúde bucal, ainda é negligenciada (14). Os produtos relacionados à higiene oral derivados de vegetais vêm ganhando bastante destaque nos estudos, onde se comprova a eficácia da ação dos produtos naturais no enfrentamento das doenças bucais e seu grande benefício para a população (Castilho, Murata \& Pardi, 2007; Bussadori, 2013; Zanin et al., 2007).

A odontologia vem realizando diversas pesquisas referentes a produtos naturais que possuam atividade farmacológica, toxicidade reduzida e biocompatibilidade, de forma que seja mais acessível para a população (Castilho, Murata \& Pardi, 2007; 
Dinguesleski et al., 2015; Machado \& Oliveira, 2014). Os compostos naturais e fitoterápicos utilizados na saúde bucal são importantes para programas preventivos e curativos, prevenindo o crescimento bacteriano, a adesão e colonização, além de ação antiinflamatória, anti-hemorrágica e anestésica (Evangelista et al., 2013; Saliasi et al., 2018). Dessa forma, os componentes de alguns produtos naturais possuem efeitos de apoio sobre a prevenção e tratamento da cárie dentária, doença periodontal, e candidíase oral (Monteiro e Fraga, 2015; Castilho, Murata \& Pardi, 2007; Saliasi et al., 2018).

Os medicamentos fitoterápicos incluem preparações e produtos naturais à base de ervas e partes de plantas e outros materiais vegetais como princípio ativo, sendo utilizados de forma individual ou associados, para uma melhor higiene oral, prevenindo inflamações, alergias, podendo até mesmo amenizar algumas doenças autoimunes (Monteiro \& Fraga, 2015; Saliasi, 2018). Os vegetais mais utilizados para a preparação dos produtos são o Alecrim, Alecrim-pimenta, Arnica, Barbatimão, Calêndula, Camomila, Cacau, Capim-limão, Cavalinha, Copaíba, Cravo-da-Índia, Equinácea, Guaco, Malva, Maracujá, Melissa, Passiflora, Romã, Rosa rubra, Salgueiro branco, Sálvia, Tansagem, Unha de gato, Alho, Malaleuca, Semente de Perilla, Manuka, Eucalipto, Alfazema, Plumbago, Xilitol, Hortelã graúda, Própolis, Tomilho, Mentol, Timol, Centelha asiática, entre outros produtos naturais que são possíveis de serem utilizados e prescritos nas atividades clínicas e diárias (Monteiro e Fraga, 2015; Evangelista, Sampaio e Parente, 2013; Gomes et al., 2020; Castilho, Murata \& Pardi, 2007; Dinguesleski et al., 2015; Bussadori, 2013; Machado e Oliveira, 2014; Zanin et al., 2007; Soares, Bonvini \& Fukushigue, 2019; Juiz, Alves e Barros, 2010). As indicações usuais desses fitoterápicos estão associadas a tratamento de infecções, inflamações, odontalgias, processos cicatriciais, mantendo uma boa saúde bucal através de produtos naturais que não tenham origem animal, destacando as formas de decocção, maceração e a infusão como formas de utilizá-los (Zanin et al., 2007).

A Própolis é um composto natural bastante conhecido na medicina popular devido à sua atividade biológica e à sua terapêutica. Diversos estudos mostraram que ela é antibacteriana, antifúngica, antiviral, imunoestimulatória, antitumoral e cicatrizante (Castilho, Murata \& Pardi, 2007, Dinguesleski et al., 2015; Bussadori, 2013; Juiz, Alves e Barros, 2010; Mota et al., 2018). Ela é uma resina natural não tóxica, coletada de várias plantas, pelas abelhas, de forma específica pela Apis melífera, sendo que sua composição varia de acordo com a região onde foi extraída (Gomes et al., 2020; Castilho, Murata \& Pardi, 2007; Dinguesleski et al., 2015). Em seus compostos isolados e suas frações pode-se observar a redução de bactérias, prevenindo cárie, candidíase e a periodontite (Castilho, Murata \& Pardi, 2007; Dinguesleski et al., 2015; Borgui, Moimaz \& Saliba, 2005). Dessa forma, as substâncias da própolis podem ser utilizadas em dentifrícios, enxaguatórios, vernizes e vaselinas, sendo um bom produto natural para terapêutica da microbiota oral (Castilho, Murata \& Pardi, 2007; Dinguesleski et al., 2015; Soares, Bonvini \& Fukushigue, 2019).

O óleo do Cravo da Índia é extraído pela destilação do seu caule, folha e flores, cuja coloração é castanho escuro, com um odor e sabor acentuados (Souza e tal., 2015; Sousa, 1994). O Cravo da Índia possui propriedades antisséptica, bactericida, fungicida, parasiticida, antimicótica, relaxante muscular, analgésico, anestésico, antidiabética, antitumoral, antiviral, antitrombótica, antiinflamatório (Affonso \& tal., 2012; Machado \& Oliveira, 2014; Valente et al., 2009; Gomes et al., 2020; Aleluia et al., 2015). A composição química do extrato do Cravo da Índia é por grupos como óleo essencial, fitoesteroides, entre outros, visto que o óleo é composto por eugenol, eugenil-acetato, chavicol (Valente et al., 2009). O Eugenol é extraído do Cravo da Índia e possui efeito antiinflamatório, cicatrizante, analgésico, antisséptico, fungicida, antimicótico, parasiticida e bactericida na cavidade oral, bastante utilizado no alívio de dores de cabeça, dentes, articulações, mau hálito e estomatites (Gomes et al., 2020; Souza et al., 2015; Mota et al., 2018). O eugenol é bastante utilizado nas odontalgias, sendo um dos responsáveis pelos efeitos farmacológicos da planta, visto que sua ação bactericida ocorre devido à alta penetrabilidade na membrana citoplasmática (Valente et al., 2009; Affonso et al., 2012).

A Hortelã graúda e o Eucalipto têm propriedades antibactericidas e a Romã possui propriedades parecidas com a clorexidina, inibindo a placa supra-gengival, o crescimento de bactérias do biofilme dental, dentre elas o Streptococcus 
Mutans, abscesso, inflamação, aftas, gengivite e periodontites, tendo ação bactericida e bacteriostática (Oliveira et al., 2007; Mota et al., 2018; Machado \& Oliveira, 2014; Bussadori, 2013; Dinguesleski et al., 2015). As substâncias como Tomilho, Camomila e a Sálvia possuem ação antisséptica, analgésica, desinfectante, hemostática, anestésica e são bastante indicados em casos de abscessos, aftas, gengivite e inflamações bucais (Borgui, Moimaz \& Saliba, 2005; Mota et al., 2018; Zanin et al., 2007; Bussadori, 2013). Já o Alecrim (Rosmarinus offinalis) possui propriedade analgésica, antisséptica, antimicrobiana, antivirais, antiinflamatória, antidematogênica, antioxidante e antiulcerogênica (Bussadori, 2013).

A Centella asiática e a Punica granatum promovem a reparação tecidual e a modulação da resposta imune; já o Naturtium officinale é utilizado em bochechos, com extrato do talo de agrião para tratamento de aftas, estomatites e gengivites devido às propriedades adstringentes, antiinflamatórias e cicatrizantes (Bussadori, 2013; Juiz, Alves \& Barros, 2010).

A Tansagem (Plantago major) é utilizada por possuir propriedades antiinflamatórias, analgésicas, antimicrobianas, antioxidantes, imunomoduladoras, antiulcerogênicas, hemostáticas e cicatrizantes, cujo uso, em casos de infecções bucofaríngeas é através da infusão e gargarejo, combatendo afeç̧ões da cavidade oral, faringe e sangramentos gengivais (Bussadori, 2013). O Alho é bastante utilizado na cultura popular. Ele possui propriedades antimicrobianas contra as bactérias orais, antifúngicas e antivirais, sendo bastante utilizado em pacientes com doença periodontal, podendo ser utilizado em enxaguatórios (Machado \& Oliveira, 2014; Castilho, Murata \& Pardi, 2007). O Guaco também é conhecido na medicina popular por possuir atividade antimicrobiana contra Streptococcus mutans; a semente de Perilla também é bastante popular na medicina Japonesa, por possuir atividade antimicrobiana sobre a Porfiromonas gingivallis e microrganismos cariogênicos (Castilho, Murata \& Pardi, 2007; Bussadori, 2013).

Há anos os óleos vegetais são utilizados como fármacos, como por exemplo, o óleo de Copaíba; quando utilizado na odontologia, tem efetividade no combate ao Streptococcus mutans. Assim como o extrato hidroalcoólico, esses óleos mostraram efeitos positivos na redução de biofilme na cavidade oral, devido a sua ação antimicrobiana e analgésica (Machado \& Oliveira, 2014; Dinguesleski et al., 2015; Evangelista et al., 2013). Os óleos essenciais de Manuka, Melaleuca, Eucalipto e Alfazema, em vários estudos mostraram-se bastante efetivos devido aos seus efeitos antibacterianos. Já o Alecrim possui propriedades antimicrobianas, analgésicas, estimulante da circulação periférica e do sistema linfático, antioxidante e rejuvenescedora (Castilho, Murata \& Pardi, 2007; Machado \& Oliveira, 2014; Cordeiro, 2005). Em alguns estudos o óleo de Manuka apresentou propriedades que inibem o crescimento bacteriano; o de Alfazema apresentou traços bacteriostáticos e os demais possuem características bactericidas ligadas à cárie dental e doença periodontal (Castilho, Murata \& Pardi, 2007).

O óleo de Plumbago possui relativa atividade antimicrobiana contra bactérias e fungos como a Candida albicans, sendo que os componentes dos óleos essenciais como o Timol, Eucaliptol e Mentol são bastante utilizados na cavidade oral em afecções, associados à colutorios (Castilho, Murata \& Pardi, 2007; Bussadori, 2013; Monteiro, 2012). Já as ações bacterianas dos óleos essenciais de Mentha arvensis estão associadas à antiespasmódica, expectorante, anti-histamínica e antisséptica, agindo sobre as cepas de Staphylococcus aureus e leveduras da Candida albicans (Monteiro, 2012). A Achilleamille folium apresenta propriedades adstringentes, antiinflamatória, antitumorais, antibacterianas e cicatrizantes, sendo utilizada em bochechos; seus óleos essenciais são utilizados em enxaguatórios bucais, auxiliando na higiene bucal, tendo como pretensão controlar as infecções orais (Bussadori, 2013).

\subsection{Produtos de higiene bucal de derivados naturais}

Existe uma diferença bastante significativa entre produtos naturais e produtos com ingredientes naturais, uma vez que não basta ter um componente natural na sua formulação, sendo necessário seguir um padrão, de forma que não possua ingredientes químicos em sua composição (Sebrae, 2008). Visto que, o órgão responsável pela fiscalização e regulamentação da utilização de fitoterápicos e derivados de plantas no Brasil é a Agência Nacional de Vigilância Sanitária, a qual possui o 
dever de proteger e promover saúde à população, garantindo segurança sanitária de produtos e serviços (Monteiro, 2012). Os produtos fitoterápicos podem ser encontrados em forma de cápsulas, comprimidos, géis, pomadas, soluções aquosas ou hidroalcoólicas e chás, além de estarem presentes em produtos como cremes dentais e enxaguantes bucais, escovas com cerdas de bambu e outros produtos de higiene oral sem testes em animais, o que vem popularizando-se bastante (Machado \& Oliveira, 2014; Mota et al., 2018; Oliveira et al, 2007).

Há muitos anos atrás, nos países como Ásia, Oriente Médio, América e África eram utilizadas escovas de dente naturais, derivadas de gravetos, talos ou raízes de várias plantas, sendo as mesmas escolhidas de acordo com suas fibras, sabores e disponibilidade (Castilho, Murata \& Pardi, 2007; Dinguesleski et al., 2015). As escovas feitas de plantas podem possuir ações contra bactérias responsáveis pela formação da cárie, uma vez que já são produzidas escovas sem corantes, com cerdas macias e de carvão vegetal antibacteriano, bucha vegetal, casca de coco, possuindo cabo de bambu, sendo as mesmas consideradas 100\% biodegradáveis (Dinguesleski et al., 2015; Borghi, Moimaz \& Saliba, 2005). O açaí serve como um grande evidenciador de placa dental, tendo sua eficácia superior aos industriais como o verde de malaquita, fucsina e eritrosina (Machado \& Oliveira, 2014).

O componente de higiene oral que vem crescendo bastante e contendo compostos naturais em sua formulação são os enxaguantes bucais, sendo indicados para o controle do biofilme, que contêm substâncias antimicrobianas, agia, etanol, flavorizantes, dentre outras (Bussadori, 2013; Saliasi et al., 2018). A utilização de enxaguantes bucais à base de produtos naturais possui o ponto positivo na questão econômica, devido à grande diversidade de ingredientes disponíveis, como Camomila, Sálvia, Mirra, Melaleuca, Eucalipto, Hortelã, Erva doce, Cálcio, Casca de Caju, Folha de Pitanga, Óleo de Copaíba e Melissa (Evangelista et al., 2013; Monteiro, 2012; Bussadori, 2013; Soares, Bonvin \& Fukushigue, 2019). O extrato de Salvadora pérsica adicionado à composição dos enxaguantes bucais possui efeitos comprovados na melhoria da condição da saúde gengival (Castilho, Murata \& Pardi, 2007). Os enxaguantes à base de ervas devem possuir ação antiplaca, antiinflamatória, atividade bacteriana e bactericida, reduzirem a adesão das bactérias no dente, inibirem o crescimento e proliferação dos microrganismos e desenvolverem um microbioma menos patogênico (Evangelista et al., 2013; Aleluia et al., 2015; Monteiro, 2012; Bussadori, 2013; Soares, Bonvini \& Fukushigue, 2019). Esses enxaguantes à base de ervas são uma grande promessa para o controle da placa bacteriana, porém sua eficácia ainda é inferior, comparado à ação antibacteriana da clorexidina (Bussadori, 2013).

As pastas de dente à base de ervas possuem propriedades antimicrobianas que variam bastante, sendo consideradas veganas as que em sua composição não possuem flúor, umectantes e emulsificantes que sejam de origem animal e não foram testadas em animais (Saliasi et al., 2018; Ducati, 2020; Sorridentes, 2020). Uma vez que as pastas de dentes tradicionais têm em sua composição umectante e emulsificante de origem animal como propilenoglicol, glicerol, adoçantes sintéticos, cores artificiais, conservantes, sabores ou fragrâncias sintéticas, componentes esses que pasta de dente considerada vegana não tem em sua composição (Saliasi et al. 2018).

Devido à grande efetividade antimicrobiana, vários produtos naturais são incorporados às pastas de dentes para controle de doenças bucais, como periodontite, gengivite e redução do biofilme (Castilho, Murata \& Pardi, 2007; Dinguesleski et al., 2015). A Macleya Cordata e a Prunella vulgaris são exemplos de produtos naturais que são inseridos em pastas de dentes, possuindo propriedades antiinflamatórias capazes de reduzirem a gengivite, assim como o Parodontax, que reduz o biofilme e o sangramento gengival (Castilho, Murata \& Pardi, 2007; Dinguesleski et al., 2015; Monteiro, 2012). Para uma higiene completa, a pasta de dente é apenas coadjuvante, ajudando na ação e no hálito fresco, já que o ato da escovação é o mais importante (Ducatti, 2020). A própolis vem sendo utilizada em pastas de dentes, antissépticos, pastilhas e pó devido à sua ação no tratamento de afecções bucais, sendo indicado em capeamento pulpar direto, irrigante intracanal, possuindo ação semelhante ao hipoclorito de sódio, agente cariostático, tratamento de doença periodontal e candidíase (Aleluia et al., 2015; 
gomes et al., 2020).

Componentes como timol, mentol e eucaliptol em óleo essencial são associados aos colutórios por possuírem grande ação antibacteriana, baixa substantividade e elevada interação com alguns componentes do biofilme bacteriano; esses óleos agem na parede celular alterando -a (Bussadori, 2013; Soares, Bonvini \& Fukushigue, 2019). Os óleos também vêm sendo introduzidos em pastas de dentes por possuírem agentes anti-biofilme e anti-gengivite. Em alguns estudos, o óleo vegetal à base de amêndoas nas pastas de dentes reduziu gradativamente a presença de Streptococcus mutans e aumentou o tamponamento salivar, sugerindo assim a substituição dos componentes abrasivos por óleos vegetais (Oliveira et al., 2007). O fio de Ráfia pode ser utilizado para realizar a limpeza interproximal, por possuir um preço mais acessível e possuir um grau de conforto razoável (Borghi, Moimaz \& Saliba, 2005).

Já o produto derivado do Cravo da Índia, disponível no mercado como óleos essenciais puros e derivados dele tem como principal aplicação na odontologia na forma de anestésico local e eugenol (Affonso et al., 2012). O eugenol extraído do Cravo da Índia é bastante utilizado na odontologia em preparação de produtos como cimentos, pastas à base de óxido de zinco e eugenol (Aleluia et al., 2015; Gomes et al., 2020).

Embora seja demonstrada uma vasta eficácia dos produtos naturais para a Odontologia, a clorexidina ainda é o enxaguatório bucal que apresenta efeito significante na redução dos índices de placa e sangramento gengival, comparada aos enxaguatórios de origem vegetal (Castilho, Murata \& Pardi, 2007). Porém, a propriedade antibacteriana da clorexidina pode ser melhorada quando combinada com os óleos essenciais, fazendo com que ocorra a redução de clorexidina em colutórios bucais, diminuindo assim os efeitos colaterais, aumentando a eficácia antimicrobiana desses antissépticos (Juiz, Alves \& Barros, 2010). Assim como todo medicamento, os produtos naturais devem ser prescritos de forma cuidadosa quanto ao uso pediátrico, por gestantes, lactantes e por indivíduos que possuam comorbidades ou fazem uso de medicamentos sintéticos, já que esses produtos naturais podem provocar reações adversas (Monteiro \& Fraga, 2015).

\subsection{Vantagens e desvantagens da utilização dos produtos naturais na Odontologia}

Como visto anteriormente, os fitoterápicos têm como propósitos a prevenção e a cura de patologias, ou ao menos a redução de seus sintomas (Aleluia et al., 2015). Assim como os medicamentos industriais, as substâncias naturais podem apresentar vantagens e desvantagens de acordo com sua utilização, sendo que os produtos naturais possuem baixo custo, são de fácil aquisição devido à grande quantidade de matéria prima, comparado aos demais medicamentos não fitoterápicos (Aleluia et al., 2015; Mota et al., 2018; Souza et al., 2015). Eles apresentam benefícios como redução do contato com substâncias químicas, custo acessível tanto para a população quanto para os serviços públicos de saúde, ótima aceitação popular, devido às reações adversas e na maioria dos casos mínimas, apresentando ação antiinflamatória, antimicrobiana, ansiolítica e cicatrizante para seus usuários (Aleluia et al., 2015; Mota at al., 2018; Sorridentes, 2020).

A utilização dos óleos na saúde bucal pode ser através de dentifrícios, antissépticos, entre outras formas, sendo que seu mecanismo de ação é baseado na salubridade da parede celular do microrganismo (Bussadori, 2013; Filogônio, 2009). Os óleos podem apresentar vantagens como baixa alergenicidade, porém quando adicionados a produtos odontológicos, possuem baixo risco de toxicidade, mesmo com indícios de ingestão; esse baixo risco está relacionado aos cimentos restauradores feitos com eugenol, pois eles não liberam grandes quantidades na saliva (Valente et al., 2009; Affonso et al., 2012). Já o Cravo da Índia pode apresentar desvantagens por ser neurotóxico, deprimindo o sistema nervoso central, podendo levar ao coma; é irritante para as mucosas, pode causar anomalias urinárias, lesões hepáticas, distúrbios de coagulação e, caso aplicado na gengiva inflamada, pode causar danos a ela, isso se administrado de forma incorreta e com doses inadequadas (Valente et al., 2009). Os produtos com a mistura de timol, mentol, eucaliptol e salicilato de metila e os demais óleos possuem mecanismo de ação que pode alterar a parede celular dos microrganismos, podendo ter efeitos colaterais como sensação de queimação e gosto 
ardido, além de necessitar de implementação de mudanças na formulação para serem implementados em enxaguantes bucais (Bussadori, 2013; Corideiro, 2005; Sebrae, 2008).

Medicamentos à base de Própolis e drogas como Dissulfiram ou Metronidazol podem causar vômitos e náuseas, se associados ao ácido caféico, podendo apresentar efeitos como erupções cutâneas, inchaço, coceira, sendo mais associado a pessoas que são alérgicas ao pólen ou picadas de abelha, com asma, grávidas (Gomes et al., 2020). Já os produtos naturais como a cúrcuma, bicarbonato de sódio ou argila possuem desvantagens por serem abrasivos ao esmalte dental, tendo que tomar um cuidado redobrado durante a higiene bucal com esses produtos (Ducatti, 2020). As pastas veganas possuem um custo benefício muito relativo, pois podem ser fabricadas em casa e os produtos utilizados podem ser da preferência do usuário, porém o cuidado deve ser dobrado para que não utilizar muita força durante a escovação, pois se utiliza argila branca e o bicarbonato de sódio, que são produtos abrasivos, com a força da escovação pode-se desgastar o esmalte dentário (Ducatti, 2020; Sorridentes, 2020).

Dessa forma, sabemos que os medicamentos fitoterápicos possuem varias utilidades como foi relatado nesse artigo, porém possui alguns efeitos colaterais como toxicidade, alergias e hipersensibilidade, podendo chegara até mesmo a choques anafiláticos, podendo causar abortos ou interagir de forma negativa com alguns medicamentos (Aleluia et al., 2015). Alguns efeitos como, alergias, inflamações e doenças autoimunes podem ser evitados se reduzirmos o contato com produtos químicos e utilizar a dosagem correta das medicações fitoterápicas (Valente et al., 2009; Sorridentes, 2020).

\section{Discussão}

A Agência Nacional de Vigilância Sanitária (ANVISA) define os medicamentos fitoterápicos como preparações exclusivas de matéria-prima vegetal ativa, vinda da mistura de uma ou mais substâncias derivadas de plantas, tendo apresentação sólida ou líquida (Gomes et al., 2020; Mota et al., 2018). Já a Organização Mundial de Saúde (OMS) define que plantas medicinais são aquelas silvestres ou cultivadas, das quais se utilizam os seus recursos para prevenção, alívio, cura ou modificação de um processo fisiológico, seja ele normal ou patológico, podendo as mesmas serem utilizadas por meio de fármacos ou de percussores (Cordeiro, 2005). Nesse quesito a OMS vem incentivando pesquisas com produtos naturais para a terapêutica na saúde pública, por estar ligado a questões de políticas de saúde e cidadania, além de ter um baixo custo e ser acessível à população (Borghi, Moimaz \& Saliba, 2005).

De acordo com Filogônio (2009), a introdução dos óleos essenciais nas pastas de dentes não afeta o equilíbrio da microbiota bucal, porém também não permite que surjam novos patógenos oportunistas. Já Cordeiro (2005) afirma que os extratos de óleos vegetais possuem maior atividade sobre bactérias Gram-positivas, mas que a sua inserção em pastas dentais e enxaguatórios bucais não faz muita diferença na atividade antibacteriana, comparadas com as sem extratos vegetais. Ainda sobre os óleos essenciais, Filogônio (2009) relata que a combinação deles em produtos odontológicos possui atividade antibiofilme, mas que depende de vários mecanismos, como a inibição da proliferação, interferência na colonização e do espectro da atividade antisséptica do produto utilizado.

Sobre a clorexidina comparada aos produtos naturais como óleos essenciais Soares et al. (2019) relatam que eles possuem a mesma finalidade de assepsia bucal, reduzindo o percentual de bactérias em intervenções cirúrgicas, enxaguatórios bucais e em pastas dentais. Bussadori (2013) alega que os enxaguatórios compostos por ervas são bastante eficazes, por serem antibacterianos e bacteriostáticos, interferindo diretamente na formação do biofilme dentário, sendo mais eficazes que os enxagutórios convencionais. Já Saliasi et al. (2018) afirmam que pastas de dente com ervas são eficazes para a redução do sangramento gengival e da inflamação, comparado às pastas convencionais.

Sobre a manipulação das ervas, Borghi et al. (2005) afirmam que é necessário um conhecimento maior, pois existem produtos naturais tóxicos que podem levar à morte, além de lembrarem que a intoxicação pelas ervas, na maioria das vezes não 
tem cura. Já Gomes et al. (2020) afirmam que a utilização da fitoterapia na odontologia deve ser cautelosa e responsável, visto que o cirurgião dentista precisa da fitoterapia, o que torna necessário a inserção dela na grade curricular obrigatória da graduação.

Para Moreira (2012), a utilização de quinosol nos enxaguantes bucais apresentam uma ótima atividade antimicrobiana frente aos microrganismos frequentemente na cavidade bucal.

Em seu trabalho Monteiro (2012), concluiu que extrato de Mentha arvensis não apresentou capacidade antimicrobiana contra cepas de $S$. mutans, porem foi exposto a necessidade da realização de mais testes para confirmar sua eficácia ou sua ausência de forma definitiva.

No estudo de Juiz (2010), é demonstrado a atividade da própolis como anti-inflamatório e como auxiliar no controle de microrganismos presentes na doença periodontal. Também é mencionado uma possível ação sinérgica favorável quando utilizado com outros fitoterápicos.

Frente a essa revisão, observa-se que existe uma necessidade de mais pesquisas e informações para os profissionais sobre a utilização da fitoterapia na odontologia. Informações essas que respondam, de forma mais acessível, às vantagens e desvantagens da sua utilização, quando utilizar e como reverter os seus efeitos, se necessário. Ressalta-se que a utilização da fitoterapia de forma alternativa é uma boa escolha para a redução de gastos e para a população carente, além de englobar os veganos e vegetarianos.

\section{Considerações Finais}

Dado o exposto, os fitoterápicos e os componentes minerais e vegetais são alternativas viáveis e podem ser utilizados no dia a dia, tanto no consultório odontológico, como para o consumo das pessoas, sendo de baixo custo, apresentando ações antibactericidas e antineoplásicas, sendo estes alguns de seus benefícios. A incorporação de substâncias naturais nos produtos odontológicos reduz riscos de exposição dos organismos a produtos sintéticos que, a longo prazo podem trazer prejuízos à saúde, algo que já vem sendo discutido na sociedade. Os componentes naturais apresentam propriedades que contribuem para o retardo ou desestabilidade da formação do biofilme, que é um dos fatores responsáveis pelo desenvolvimento de doenças como periodontais e cárie.

\section{Referências}

Affonso, R. S., Rennó, M. N., Slana, G. B. C. A., \& França, T. C. C. (2012). Aspectos químicos e biológicos de óleo essencial de cravo da índia. Rev Virtual Quim. 4(2):146-61.

Aleluia, C. M., Procópio, V. C., Oliveira, M. T. G., Furtado, P. G. S., Giovannini, J. F. G., \& Mendonça, S. M. S. (2015). Fitoterápicos na odontologia. Rev Odontol Univ Cid São Paulo. 27(2):126-34.

Borghi, W. M. M. C., Moimaz, S. A. S., \& Saliba, N. A. (2005). Métodos alternativos para higienização bucal e terapêutica odontológica. Rev Inst Ciênc Saúde. 23(4):309-14.

Bussadori, C. M. (2013). Avaliação de enxaguatório bucais na atividade biológica do biofilme formado em braquetes ortodônticos. Dissertação. Universidade de São Paulo, São Carlos, SP, Brasil.

Castilho, A. R., Murata, R. M., \& Pardi, V. (2007). Produtos naturais em odontologia. Rev saúde. 1(1):11-9.

Cordeiro, C. H. G. (2005). Atividade biológica de gel dentifrício e enxaguatório bucal contendo extratos vegetais. Dissertação. Faculdade de Ciências Farmacêuticas, Araraquara, SP, Brasil.

Dinguesleski A. H., Thomas, G. V., Mello, A. M. D., \& Mello, F. A. Z. (2015). Associação de agentes fitoterápicos em dentifrícios. Rev gestão e Saúde. $13: 11-6$.

Ducatti, S. A. R. (2020). Mais do que uma moda passageira, a pasta de dente vegana pode trazer benefícios tanto para a saúde quanto para o meio ambiente. https://simpatio.com.br/pasta-dente-vegana/

Evangelista, S. S., Sampaio, F. C., Parente, R. C., \& Bandeira, M. F. C. L. (2013). Fitoterápicos na odontologia: estudo etnobotânico na cidade de Manaus. Rev Bras Pl Med. 15(4):513-9. 
Filogônio, C. F. B. (2009). Estudo comparativo do efeito de óleos vegetal e mineral contidos em dentifrício no controle do biofilme dentário. Dissertação. Universidade Católica de Minas Gerais, Belo Horizonte, MG, Brasil.

Gomes, M. S., Mendonça, A. K. P., Cordeiro, T. O., \& Oliveira, M. M. B. (2020). Uso de plantas medicinais na odontologia: uma revisão integrativa. Rev Ciênc Saúde Nova Esperança. 18(2):118-26.

Juiz, P. J. L., Alves, R. J. C., \& Barros, T. F. (2010). Uso de produtos naturais como coadjuvante no tratamento da doença periodontal. Rev Bras Farmacogn. 20(1):134-9.

Machado, A. C., \& Oliveira, R. C. (2014). Medicamentos fitoterápicos na odontologia: evidencias e perspectivas sobre o uso de aroeira-do-sertão (Myracrodruon urundeuva Allemão). Rev Bras Pl Med. 16(2):283-9.

Monteiro, E. M. H. (2012). Desenvolvimento de solução enxaguatória bucal bifásica contendo extratos naturais de plantas. Dissertação. Universidade Federal de Juiz de Fora, Juiz de Fora, MG, Brasil.

Monteiro, M. H. D. A., \& Fraga, S. A. P. M. (2015). Fitoterapia na odontologia: levantamento dos principais produtos de origem vegetal para saúde bucal. RevFitos. 9(4):253-303.

Moreira, M. J. S., Ferreira, M. B. C., \& Hashizume, L. N. (2012) Avaliação in vitro da atividade antimicrobiana dos componentes de um enxaguatório bucal contendo malva. Pesq Bras Odontoped Clin Integr. 12(4)505-9.

Mota I. B. O., Cunha L. S., Braga L. L. A., Lima C. C., \& Dietrich L. (2018) Fitoterapia na odontologia: levantamento dos principais produtos fitoterápicos usados para a saúde bucal. Psicol Saúde Debate. 4(1):71.

Oliveira, F. Q., Gobira, B., Guimarães, C., Batista, J., Barreto, M., \& Souza, M. (2007) Espécies vegetais indicadas na odontologia. Rev Bras Farmacogn. 17(3):466-76

Saliasi, I., Llodra, J. C., Bravo, M., Tramini, P., Dussart, C., Viennot. S. et al. (2018) Efeito de um creme dental / enxaguatório bucal contendo extrato de folha de Caricapapaya no sangramento gengival interdental: um ensaio clínico randomizado. Int J Environ Res Saúde Pública. 15(12):26-60.

Sebrae. (2008). Cosméticos a base de produtos naturais. http://www.funcex.org.br/material/redemercosul_b ibliografia/biblioteca/ESTUDOS_BRASIL/BRA_167.pdf

Soares, A. K., Bonvini, B., \& Fukushigue, C Y. (2019). Avaliação do potencial antimicrobiano profilático de enxaguatórios bucais contendo em sua formulação clorexidina e óleos essenciais. Rev Salusvita. 38(1):87-96.

Sorridentes. Pasta de dente vegana: veja os prós e contras da sua utilização. https://sorridents.com.br/blog/pasta-de-dente-vegana-veja-os-pros-e-contras-dasua-utilizacao/

Sousa Neto, M. D. (1994) Estudo da influência de alguns óleos vegetais adicionados ao eugenol sobre as propriedades físico-químicas do cimento obturador dos canais radiculares do tipo Grossman. Dissertação. Universidade de São Paulo, Ribeirão Preto, SP, Brasil.

Souza, R. L. M., Vettorazzi, M. R., Kobayashi, R. K., \& Furtado Neto, M. A. A. (2015). Eugenol como anestésico no manejo de ariacó Lutjanussynagris (Linnaeus, 1758), cultivado. Rev Ciênc Agron. 46(3):532-8.

Valente, R. O. H., Sampaio, F. C., Souza, I. A., \& Higino, J. S. (2009). Estudo toxicológico pré-clinico (agudo) do extrato do Syzygiumaromaticum (L) in rodents. Rer bras farmacogn. 19(2):557-60.

Zanin, S. M. W., Miguel, M. D., Barreira, S. M. W., Nakashima, T., Cury, C. D., \& Costa, C. K. (2007). Enxaguatório bucal: principais ativos e desenvolvimento de fórmula contendo extrato hidroalcoólico de Salviaofficinalis L. Rev Visão Acadêmica. 8(1):19-24 